\title{
Intra-operative squash cytodiagnosis of pleomorphic xanthoastrocytoma : A diagnostic challenge
}

\author{
Binayke R ${ }^{1}$, Agale S.V ${ }^{2}$, Kumari G ${ }^{3}$, D'Costa G. F ${ }^{4}$ \\ ${ }^{1}$ Dr. Rachana Binayke, Assistant Professor, ${ }^{2}$ Dr. Shubhangi Vinayak Agale, Associate Professor, ${ }^{3}$ Dr. Geeta Kumari, \\ Resident, ${ }^{4}$ Dr. Grace. F. D'Costa, Professor and HOD, all authors are affiliated with Department of Pathology, Grant \\ Government Medical College, Mumbai, India
}

Address for Correspondence: DR. Rachana Binayke, Pathology, Assistant Professor, Department of Pathology, Grant Government Medical College, Mumbai. Email-id- rbinayke@gmail.com

\begin{abstract}
Pleomorphic xanthoastrocytoma (PXA) is WHO grade II tumor representing less than $1 \%$ of all astrocytic tumors. It displays cellular atypia and pleomorphism to such an extent that it can be misdiagnosed as a high grade glioma thereby posing a diagnostic challenge especially during intraoperative squash preparations. The present case is a 16-yr-old boy with history of seizures and CT Brain showed a mass located in the right temporal lobe. The intraoperative cytological diagnosis of low grade glioneuronal tumor was rendered.Pleomorphic xanthoastrocytoma was confirmed on histopathology and immunohistochemistry. This challenging case highlights the salient cytomorphologic features of this tumor along with differential diagnosis.
\end{abstract}

Key words: Pleomorphic xanthoastrocytoma, Intraoperative squash cytodiagnosis, Differential diagnosis

\section{Introduction}

Pleomorphic xanthoastrocytoma (PXA) first described by Kepes et al [1] is an uncommon astrocytic tumor arising in supratentorial location with predilection to the temporal lobe representing less than $1 \%$ of all astrocytic tumors [2]. It belongs to grade II of the WHO histological classification of tumors of the CNS [3]. However, 9-20\% of PXAs have been reported to undergo malignant transformation and some of them exhibit anaplastic features at the first presentation [4]. It can be easily confused with high grade glioma and hence accurate cytologic differentiation is necessary to determine adequate therapy during surgery [5]. We present a case of PXA in 16 year old boy diagnosed on intraoperative squash cytology as low grade glioneuronal tumor and only after thorough clinicradiological correlation confirmed histologically as pleomorphic xanthoastrocytoma.

\section{Case Report}

A 16 year old boy presented with complaints of two episodes of seizures during last 3 months which were generalized tonic clonic type lasting for 5 minutes and not associated with post ictal loss of consciousness. CT Brain revealed well defined solid cystic heterogenous lesion measuring $4.2 \times 3.5 \times 3 \mathrm{~cm}$ in right anterior temporal lobe (Fig 1) suggestive of neoplastic etiology. The patient underwent a stereotatic-guided craniotomy and intra-operative cytological preparation revealed high cellularity with polymorphous cell population ranging from spindled to plump to predominant giant pleomorphic forms. The tumor cells were highly bizarre, varied in shape from round to elongated and had large, giant multilobed, hyperchromatic monstrous nuclei with abundant sometimes vacuolated cytoplasm. However no mitotic figures and necrosis .with the above cytological features an intra operative squash diagnosis of low grade glioneuronal tumor was rendered (Fig 2 a,b,c and d). The tumor was totally resected subsequently and the fragmented mass

Manuscript received: $30^{\text {th }}$ March 2017

Reviewed: $09^{\text {th }}$ April 2017

Author Corrected: $16^{\text {th }}$ April 2017

Accepted for Publication: $25^{\text {th }}$ April 2017 
biopsies were received totally aggregating to about $1.5 \mathrm{x} 1.5 \mathrm{x}$ I cms. H \& E sections revealed a tumor with heterogeneous histologic appearance composed of spindle cells arranged in fascicles and storiform pattern, together with an admixture of variably hyperchromatic pleomorphic giant cells, the nuclei of which were bi and multinucleated (Fig.3a and b). Large xanthomatous cells served as a helpful diagnostic feature (Fig.3c,d). The tumor was reticulin rich and Periodic acid Schiff stain highlighted eosinophilic hyaline globular bodies. Immunohistochemically, tumor cells were positive for glial fibrillary acidic protein (Fig 4a) and negative for chromogranin (Fig 4b), vimentin, synaptophysin and CD99, and bcl-2 and neuron specific enolase (NSE). Ki-67 proliferation index was $0.5 \%$ (Fig 4c). Final diagnosis was WHO grade II PXA. The eleven month follow up in this case did not reveal any evidence of local recurrence nor metastatic spread and the patient is doing well.

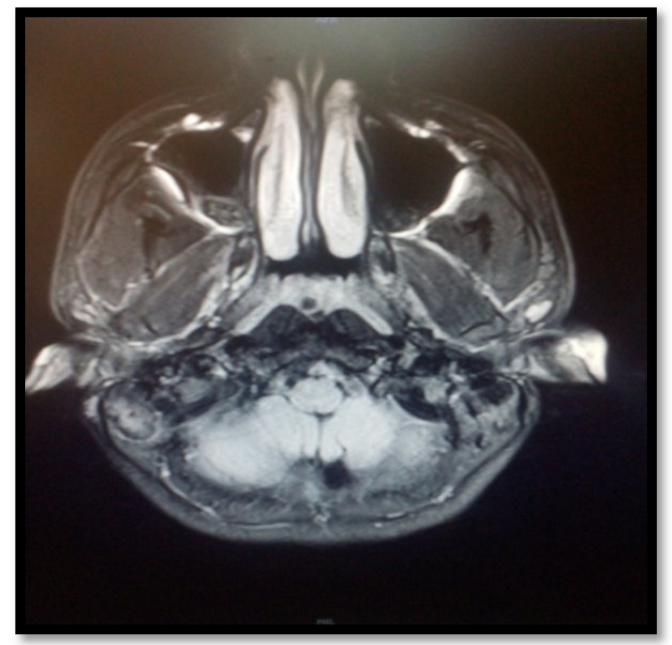

Fig-1: CT Brain revealed a well circumscribed solid cystic heterogeneous lesion measuring $4.2 \times 3.5 \times 3 \mathrm{~cm}$ involving right anterior temporal lobe
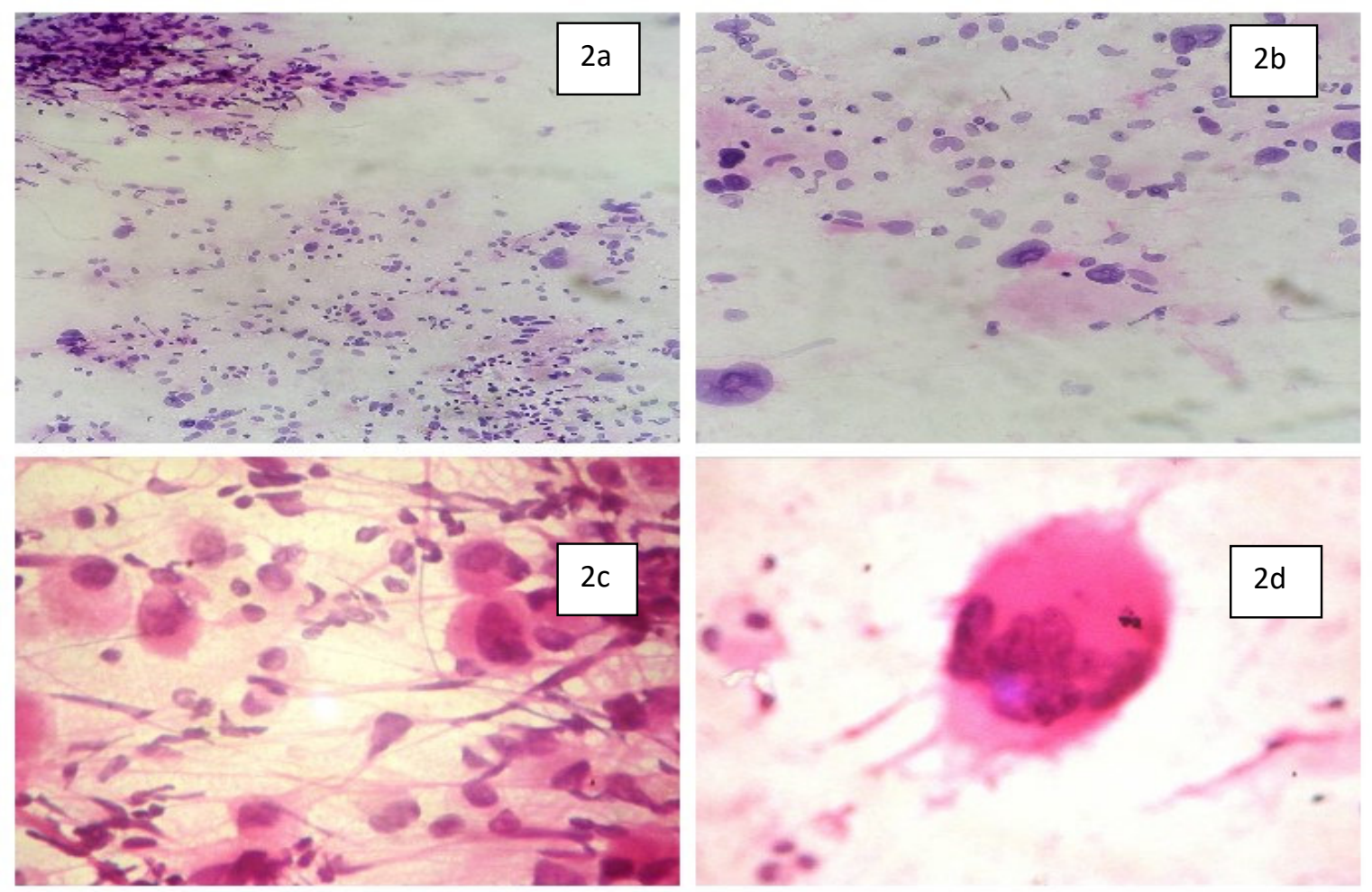

Fig 2: Squash Cytology Smears, Fig 2a and b: showing polymorphous cell population, Fig 2c: showing large cells with binucleation, Fig 2d: showing multinucleate giant cell. 

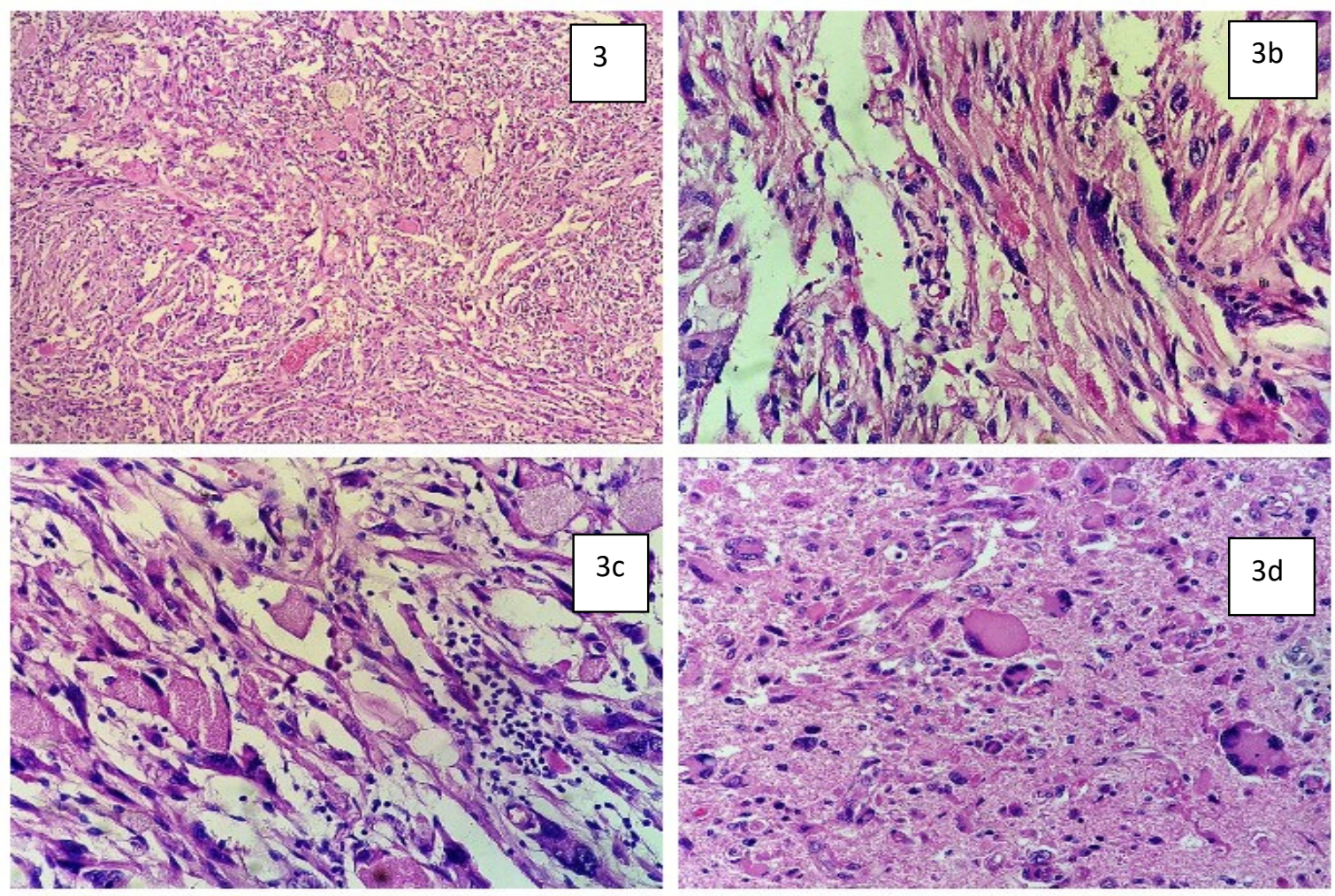

Fig 3: Histopathology sections ( $\mathrm{H}$ \& E), Fig 2a and b: showing highly cellular tumor with polymorphous cell population, Fig 2c: showing large xanthomatous cells, Fig 2d: showing large cells with abundant eosinophilic cytoplasm and multinucleate giant cells.
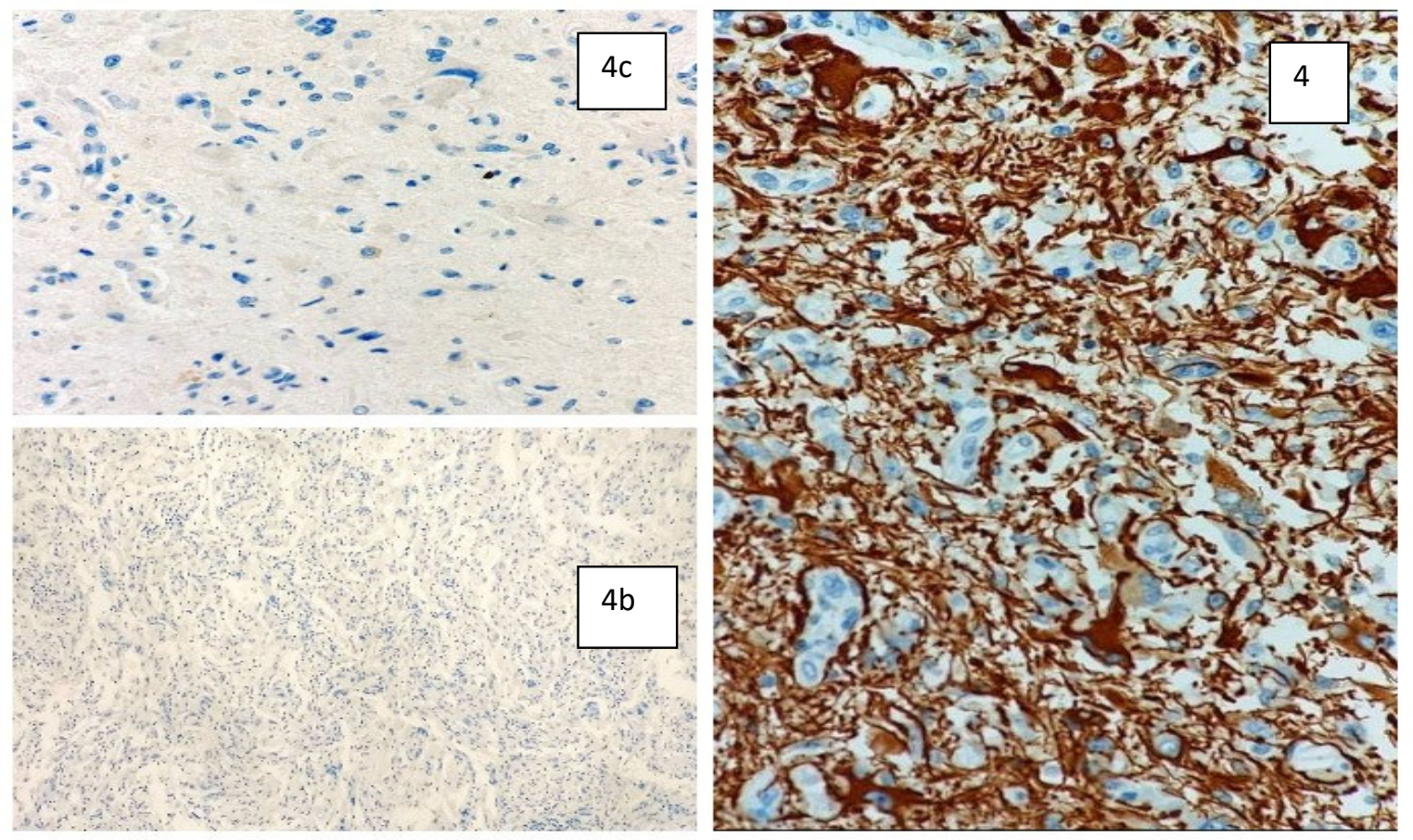

Fig 4 : Immunohistochemistry markers, Fig 4a: GFAP positive, Fig 4b: Chromogranin negative, Fig 4c: Ki-67 proliferative index low $(0.5 \%)$ 


\section{Discussion}

Pleomorphic xanthoastrocytoma first described by Keeps et al.[1] in 1979 as a distinctive astrocytic neoplasm with a comparatively good prognosis accounts for less than $1 \%$ of all astrocytic neoplasms. Because of the superficial cerebral location of the lesion, many patients present with a fairly long history of seizures [2]. It is typically encountered in children and young adults without gender predilection and characteristic histological features include pleomorphic and lipidized cells expressing GFAP and often surrounded by areticulin network as well as eosinophilicgranular bodies [3]. Before the introduction of immunostaining, pleomorphic xanthoastrocytomas were thought to represent mesenchymal neoplasmsof the meninges and brain, partly because the lipidized neoplastic glial cells resemble "xanthoma" cells, and partlybecause many tumour cells produce abasement membrane. However, immunohistochemical and ultrastructural studies have clearly shown that the tumour cells are neoplastic astrocytes, often with evidence of neuronal differentiation [3] Anaplastic pleomorphic xanthoastrocytoma, WHO grade III, has been added to the 2016 CNS WHO as a distinct entity, requires 5 or more mitoses per 10 high-power fields; necrosis may be present $[4,5]$.

The advances in the surgery of epilepsy has led to increase in the frequency of superficial hemisphererelated Tumors [6]. There is a need for the neuropathologists to sharpen their diagnostic skills for reporting of intaroperative squash smears which is a rapid, reliable, simple technique for intraoperative consultation in neurosurgical practice with high overall accuracy ${ }^{7}$ In this list of differential diagnosis complete resection is possible in most of the cases, with excellent long-term results and without any need for adjuvant treatment. PXA may be a diagnostic challenge both on the intraoperative squash smears and frozen and paraffin sections.

The clinical and radiological mimickers of PXA are dysembryoplastic neuroepithelial tumors (DNTs) which are intracortical multinodular and the smear findings include a dual population of small, oligodendrocyte-like cells and scattered, normal-looking neurons, which are loosely arranged in a myxoid background, Gangliocytomas and gangliogliomas possess characteristic dysmorphic neurons and cytology findings include spindle cells, small, gemistocyte-like cells, and desmoplastic tissue fragments in DIA coupled with small to large neurons in DIG.

In the present case the squash smears revealed predominance of giant cells. Giant cells can be found both in low grade neoplasia such as pleomorphic xanthoastrocytoma (PXA), subependymal giant cell astrocytoma (SEGA), and high grade neoplasms such as giant cell glioblastoma, anaplastic oligodendroglioma, and anaplastic ependymoma.

Squash preparations in PXA show high cellularity composed of markedly pleomorphic cellsgemistocyte-like, spindle, epithelioid, and giant bizarrewith long processes and multiple or multilobed nuclei. Xanthomatous change, with intracytoplasmic lipid droplets, and EGBs may also be present as in our case. SEGA is frequently associated with tuberous sclerosis and located in lateral ventricle. Giant cell glioblastoma is another entity in the differential diagnosis. The smears of this entity show high cellularity composed of numerous malignant astrocytic tumor cells on a necrotic background. These tumors exhibit increased mitotic figures, necrosis and prominent microvascular proliferation $[7,8]$.

In our case besides extensive cell pleomorphism, there were no other features suggestive of anaplasia such as necrosis, microvascular proliferation, and mitotic activity. In addition, the tumor exhibited some features which were indicative of slow growth such as low Ki67 proliferation index, and hence, the tumor was diagnosed as WHO grade II $[9,10]$.

\section{Conclusion}

Intra operative cytology should never be done in isolation without clinical and radiologic evaluation of the case.Despite their nonaggressive clinical behavior, PXA is the group of tumors that is most easily overgraded during intraoperative consultation, and they are frequently mistaken for high grade glioma.Because of the extreme rarity of PXA, reports of cases with cytologic, histopathologic, and clinical features have great significance.

Funding: Nil, Conflict of interest: None initiated, Perission from IRB: Yes

\section{References}


1. Kepes JJ.Rubeinstein L.J,Eng F.Pleomorphic xanthoastrocytoma-a distinctive meningocerebral glioma of young subjects.A study of 12 cases.Cancer $1979 ; 44: 1839-52$

2. Kepes JJ. Pleomorphic xanthoastrocytoma: the birth of a diagnosis and a concept. Brain Pathol. 1993 Jul;3(3):269-74.

3. Giannini, C., Paulus, W., Louis, D.N. and Liberski, P. (2007) Pleomorphic Xanthoastrocytoma. In: Louis, D.N., Ohgaki,H., Wiestler, O.D. and Cavenee, W.K., Eds, World Health Organization Classification of Tumours, WHO Classification of Tumours of the Central Nervous System, IARC Press, Lyon, 22-24.

4. David N. Louis, Arie Perry, Guido Reifenberger et al Anaplastic Pleomorphic xanthoastrocytoma The 2016 World Health Organization Classification of Tumors of the Central Nervous System: a summary Acta Neuropathol

5. Kobayashi S, Hirakawa E, Haba R. Squash cytology of pleomorphic xanthoastrocytoma mimicking glioblastoma. A case report. Acta Cytol. 1999 JulAug;43(4):652-8.
6. Lacruz CR, Catalina-Fernández I, Bardales RH, Pimentel J, López-Presa D, Sáenz-Santamaría J. Intraoperative consultation on pediatric central nervous system tumors by squash cytology. Cancer Cytopathol. 2015 Jun;123(6):331-46. doi: 10.1002/cncy.21537.

7. Krishnani N, Kumari N, Behari S, Rana C, Gupta P. Intraoperative squash cytology: accuracy and impact on immediate surgical management of central nervous system tumours. Cytopathology. 2012 Oct;23(5):30814. doi: 10.1111/j.1365-2303.2011.00905.x. Epub 2011 Aug 15.

8. Cakir E, Kucuk U, Ersen A, Pala EE, Senoglu M, Binatli AO, Yildirim Z. Intraoperative squash cytology and histology of giant cell ependymoma: A diagnostic dilemma. J Cytol. 2017 Jan-Mar;34(1):63-65. doi: 10.4103/0970-9371.197625.

9. Burger, P.C. and Scheithauer, B.W. (2007) Pleomorphic Xanthoastrocytoma. In: Burger, P.C. and Scheithauer, B.W.,Eds, Tumors of the Central Nervous System, AFIP, Washington DC, 106-113.

10. Sharma, A., Nand Sharma, D., Kumar Julka, P. and Kishor Rath, G. (2011) Pleomorphic Xanthoastrocytoma-A Clinico-Pathological Review. Neurologia i Neurochirurgia Polska, 45, 379-386.

\section{How to cite this article?}

Binayke R, Agale S.V, Kumari G, D'Costa G. F. Intra-operative squash cytodiagnosis of pleomorphic xanthoastrocytoma A diagnostic challenge. J PediatrRes.2017;4(04):279-283.doi:10.17511/ijpr.2017.i04.07. 